\title{
Effect of mental disorders on the association between bullying, suicidality and self-harm among Australian adolescents: A mediation analysis using data from a nationwide survey
}

Md Irteja Islam ( $\square$ irteja.islam@icddrb.org )

University of Southern Queensland Faculty of Business Education Law and Arts

https://orcid.org/0000-0001-7637-5907

Rasheda Khanam

University of Southern Queensland

Enamul Kabir

University of Southern Queensland

Research article

Keywords: Traditional bullying, Cyberbullying, Mental disorder, Depression, ADHD, Anxiety, Conduct disorder, Suicidality, Self-harm, Adolescents

Posted Date: September 4th, 2020

DOI: https://doi.org/10.21203/rs.3.rs-67812/v1

License: (c) (1) This work is licensed under a Creative Commons Attribution 4.0 International License.

Read Full License 


\section{Abstract \\ Background}

Recent research has depicted that both traditional and cyber bullying victimization report serious mental health issues, particularly suicidal and non-suicidal self-harm in adolescents. However, the little is known about the mechanism underlying the correlation between bullying and risk behaviours - suicidality and self-harm. This study aimed to examine the effect of bullying victimization on suicidal and non-suicidal self-harm, and the mediating effect of mental disorders (major depressive disorder, ADHD, conduct disorder and anxiety disorder) on the relationship between bullying victimization, suicidality and selfharm among adolescents.

\section{Methods}

Data for this study came from the Young Minds Matter: the second Australian Child and Adolescent Survey of Mental Health and Wellbeing and Youth dataset, which is a cross-sectional nationwide survey. A total of 2166 adolescents aged $12-17$ years $(M=14.83 ; S D=1.61 ; 52.2 \%$ boys) were analyzed. Baron and Kenny's approach with regression analysis was employed to test the mediation effect of each mental disorder on the association between traditional and cyber bullying victimization, suicidality and selfharm. Further, the Sobel test was used to statistically assess whether the indirect effects of bullying victimization on suicidality and self-harm were significant via mental disorder.

\section{Results}

Overall, 622 (28.7\%) and 255 (11.8\%) of adolescents reported traditional and cyberbullying victimization, respectively. The analysis showed that victims of both bullying incurred a significantly higher risk of suicidality and self-harm among adolescents. The effect of both bullying victimization on suicidality and self-harm was mediated by major depressive disorder after adjusting for the effect of potential sociodemographic characteristics, substance use, sedentary activities. While anxiety disorder only mediated the relationship between traditional bullying, and suicidality and self-harm. ADHD and conduct disorder had no mediating effect.

\section{Conclusions}

Depression and anxiety disorder plays a mediating role in the association between bullying victimization, suicidal and self-harming behaviour. Thus, addressing such mental disorders among bullying victims is worthwhile to prevent suicidality and non-suicidal self-harm, and ultimately suicide.

\section{Background}


Suicidality and non-suicidal self-harm in adolescents are considered to be a serious public health concern and has contributed heavily to the burden of disease globally and in Australia (1-3). For instance, recent estimates showed that suicide rates among 10-24 year-olds risen $56 \%$ in 2017 from 2007, and suicide is the second leading cause of death among this age group in the US (4). While in Australia it is the topmost cause of death among 15-24 year-olds age group $(2,5)$. In Australia, the prevalence of suicidality (ideation, plan and attempt) and non-suicidal self-harm among 12-17 year-olds was most recently estimated to be $7.9 \%$ and $7.8 \%$, respectively $(6,7)$. Since the rates of suicide and self-harm have not changed significantly in the 5-year period between 2014 and 2018 in Australia (8), these troubling statistics add to the urgent need to provide research evidence to determine the determinants of suicidality and self-harm among the population. Studies reported that one of many potential predictors of suicidality and self-harm is bullying victimization $(6,9)$.

Bullying may be traditional (e.g. physical, verbal, relational) and cyber; is a repetitive and deliberately harmful act of aggression involving a power imbalance between perpetrator and victim (9-11). Childhood bullying victimization is recognized as a major public health issue in developed worlds including Australia because of its high prevalence and its enduring contribution to mental health problems $(1,12,13)$. Studies in Canada and the Netherlands found that approximately 10\%-30 percent of adolescents are frequently abused as victims, perpetrators or both $(14,15)$. Throughout Australia, latest figures indicate that in the past 12 months at least one in four adolescents experienced bullying (1). A recent study reported that $28.7 \%$ of adolescents experienced traditional bullying and about $11 \%$ of adolescents were a victim of cyberbullying (6). Given the increasing number of bullying victims, the harmful effects of bullying on victims needs to be investigated (16).

There is evidence that bullying precedes more adverse impacts on children with mental health issues, which may lead to extremely negative effects on mental wellbeing at adulthood $(17,18)$. Evidence has also shown that bullying victims were often associated with low self-esteem, depression, anxiety and violent behaviour $(1,17)$. Several studies have also reported the association between traditional bullying and suicidality and self-harm in children and adolescents $(12,19)$. In addition, studies found depression to be a mediator in the relationship between traditional bullying victimization and suicidality (11). However, research on the effect of cyberbullying on psychological outcomes has just begun $(16,20)$. Some researchers suggest that cyberbullying tends to have similar consequences as traditional bullying; others believe cyberbullying can be more stressful than traditional one $(18,21)$. Recently, an emerging research body has begun to relate cyberbullying with its psychopathology and negative outcomes such as suicidality and self-harm in children and adolescents to solve this debate $(16,21)$. For example, Islam et al. (6) and Extremera et al. (21) reported that cyberbullying is significantly associated with depression, anxiety, substance use, suicidal and self-harming behaviour among adolescents.

However, the psychological mechanisms underlying the causal link between bullying victimization and suicidality and non-suicidal self-harming behaviour are not clear. According to Agnew's theory of deviance in social psychology, social ties and incidents cause an individual to commit acts of deviation such as suicidality and self-harm (22). Bullying is one of the sources of strain, which can anger and upset 
the victim and thus make them more likely to be unearthed $(23,24)$. It means that the victims of bullying are more vulnerable to suicide and to self-harm than dealing with their bullying. Since depression and mental illnesses are well-known risk factors for suicidality and self-harm (25-27), the victims of bullying may first undergo episodes of mental health problems before moving into suicidal and self-harming behaviour (Fig. 1).

Evidences mostly from the international literatures, has documented the mediating role of depression only on the relationship between traditional bullying victimization and suicidality $(27,28)$. However, none of them have included both types of bullying (traditional and cyber), non-suicidal self-harm and other mental health disorders such as attention-deficit-hyperactivity-disorder (ADHD), conduct disorder and anxiety disorders as a mediator in their analysis. In Australia, studies mostly were state-wide focusing on individual types of bullying, risk factors or mental health issues $(1,29,30)$. Moreover, only Ford et al. (1) and Islam et al. (6) presented population-based estimates regarding the association of bullying with mental disorders, suicidality and self-harm health among Australian and adolescents. However, none investigated whether the association is mediated by mental disorders or not. Thus, the effects of different types of bullying (traditional and cyber) on suicidality and self-harm concerning mental disorders are not clear. This research gap shows an urgent need for understanding the interplay of bullying, mental disorder, and suicidality and self-harm from policy perspective to prevent the risk of child suicidality and self-harm.

This paper therefore aimed to examine the association between bullying victimization (traditional and cyber) with suicidality (ideation, plans or attempts) and non-suicidal self-harm among and adolescents aged 12-17 years, and to test separately whether each mental disorders (major depressive disorder, $A D H D$, conduct disorder and anxiety disorder) is one of the mechanisms via which bullying affects suicidality and self-harm in and adolescents. In the current study, we tested a hypothesized mediation model (Fig. 1) and predicted that there will be higher probability of suicidality and self-harm among bullying victims, and that mental disorders would mediate these relationships, while adjusting for potential sociodemographic covariates.

\section{Methods}

\section{Data source}

This study analyzed a nationwide cross-sectional data from Young Minds Matter (YMM): the second Australian Child and Adolescent Survey of Mental Health and Wellbeing that follow a random probability based sample of 5500 Australian children and adolescents aged 4-17 years. The survey was conducted in 2013-14 in collaboration between The University of Western Australia (UWA), Roy Morgan Research and the Australian Government Department of Health (AGDH). YMM was ethically approved respectively from the Human Research Ethics Committees of AGDH and UWA $(31,32)$. 
A multi-staged, area-based sampling technique was used in the survey to ensure the proportional distribution of geographic areas and representativeness of the households across the Australia. The study participants were selected from households that consented to willingly participate in the survey; where if more than one qualifying child resided in the household, a single child was randomly sampled. Overall, 6310 parents of $4-17$ years-aged (55\% of qualifying households) and 2967 adolescents of $11-$ 17 years were participated in the study. Data were collected through face-to-face interviews by trained interviewers from parents using a structured questionnaire; while adolescents completed a computerbased self-reported questionnaire privately at home to provide information related to health-risk behaviours (e.g. bullying, mental disorders, suicidality, self-harm, substance use, service use). However, few samples were excluded from the survey of most remote regions, homeless children and adolescents, institutions and any household where English-language interviews were not conducted. A more detailed of the methods have been described elsewhere (31).

\section{Measures}

\section{Suicidality and self-harm (Outcome variables)}

In the YMM survey, the Standard High School questionnaires of the Youth Risk Behavior Survey (33) were utilized to asses suicidality (ideation/plan/attempt) and self-harm only among 12-17 years aged adolescents (self-reported data), where all answers were kept confidential (25). Suicidality was assessed with the question: 'During the past 12 months, did you ever seriously consider attempting suicide?'. While, regarding self-harm, the following question was asked: 'Have you ever deliberately done something to yourself to cause harm or injury, without intending to end your own life?' $(25,26)$. All response options were coded 1 for 'Yes' and 0 for ' $N$ o'.

\section{Bullying (Independent variable)}

Items measuring bullying were collected from the Olweus Bully-Victim Questionnaire and from the Cyber Friendly Schools Project at Edith Cowan University, and were modified according to the YMM survey objectives $(34,35)$. Traditional bullying was considered 'when people tease, threaten, spread rumours about, hit, shove, or hurt other people over and over again' and cyberbullying was measured 'when people use mobile phones or the internet to send nasty or threatening emails or messages, post mean or nasty comments or pictures on websites like Facebook, or have someone pretend to be them online to hurt other people over and over again'. It was not considered bullying when two individuals of equal intensity or power discuss or battle each other amicably (35).

Adolescents were directly asked about traditional bullying and cyberbullying victimization using the following question: 'In the past 12 months, have you ever been bullied or cyberbullied?' with the listed bullying types: 'Hit, kicked, or pushed around', 'Made fun of or teased in a mean and hurtful way', 'Lies, rumours or nasty stories were spread', 'Threatened or made afraid', 'Deliberately ignored, left out on purpose or not allowed to join in', 'Other young people stole things or from me, or broke or damaged my things deliberately', 'Teased about my race, the colour of my skin or my religion', 'Sent nasty messages by 
email, mobile phone, or on the internet', 'Nasty messages or pictures were sent about me to other young people via mobile phone, internet or email', and 'Nasty comments or pictures were sent or posted about me on websites (e.g. Facebook or Twitter)'(35). For traditional bullying and cyberbullying victimization responses included 'Yes' (coded as 1 ) or 'No' (coded as 0 ).

\section{Sociodemographic characteristics (Covariates)}

The following sociodemographic covariates were included in the study: age (as continuous variable), gender (Boys/Girls), country of birth (Australia/Overseas), and location (major cities/regional and remote), school grade (Grade 7-Grade 12), family type (children from original biological parents/children from other parents like step or blended), family income $(<52000$ as low $/ \$ 52000-\$ 129999$ as medium/>\$130000 as high). For substance use a dichotomous variable (Yes/No) was created and were measured using the questions: 'Have you ever tried cigarette smoking, even one or two puffs?'; 'Have you ever had at least one drink of alcohol, other than a few sips?'; 'Have you ever tried cannabis/marijuana' and 'Have you ever used illegal drugs, or sniffed petrol, glue, aerosol, paints, solvents or nitrous?'(32).

Also, sedentary activities were measured by two items: 'In a typical day, how much time do you usually spend (I) using internet on the computer, mobile or tablet, including accessing social media such as Face book or Twitter, emailing, looking at websites or chatting online, (II) playing electronic games, such as Xbox or similar console, online, on a handheld device, computer, or mobile phone.' For each question, children and adolescents were asked to provide an average number of hours spent in a day (36). In this study, two categories 'internet use' and 'electronic game-play' were generated and coded as 0 ( $\leq 2$ hours/day) and 1 (>2 hours/day).

\section{Mental disorders (Mediator)}

The Diagnostic Interview Schedule for Children IV (DISC-IV) were selected for the inclusion of mental disorders in the survey $(37,38)$. Mental disorders in the 12-months prior the survey included: major depressive disorders, attention-deficit hyperactivity disorder (ADHD), conduct disorder and anxiety disorder (i.e. covers modules for social phobia, separation anxiety disorder, generalized anxiety disorder and obsessive-compulsive disorder) $(31,32)$. Response options for each category included 'Yes' (coded as 1 ) or ' $\mathrm{No}$ ' (coded as 0 ).

\section{Statistical analysis}

In this study, the analysis was restricted to adolescents aged 12-17 years due to paucity of information on outcome variable. Also, the 'Don't know' and 'Prefer not to say' responses were omitted. Finally, a total of 2166 adolescents were included in the analysis after combining self-reported child data and parent data to achieve study objectives.

Data were analyzed using Stata/SE 14.1 (SataCorp, College Station, TX, USA). Descriptive statistics were reported and the significance of difference was calculated using the Pearson Chi-square test, which signified the strength of the bivariate relationships between these characteristics and reports of bullying victimization. Then, a series of multivariate logistic models were used to investigate the role of mediator 
(each mental disorder) on the associations of independent variable (traditional bullying and cyberbullying victimization) with the outcome variables (suicidality and self-harm). Potential confounders included in the analysis were age, gender, location, school grade, family type, household income, time spent on internet use and electronic game-play and substance use by the child.

\section{Test for mediation}

The mediating role of mental disorders on the associations of bullying victimization (traditional and cyber) with suicidality and self-harm was examined using Barron and Kenny's four step approach (39), in which a series of regression analyses were conducted and significance of the odds was examined at each step. Figure 1 shows the hypothesized mediation model for the study of the relationship between bullying (traditional and cyber) and suicidality and self-harm. The conditions necessary to investigate such a mediating relationship require: (i) a significant association between independent variables (traditional and cyberbullying) and dependent variables (suicidality and self-harm) (Step 1 - Path C, Fig. 1); (ii) a significant relationship between independent variables and assumed mediator (each mental disorder) (Step 2 - Path A, Fig. 1); and (iii) a significant association between assumed mediator and dependent variables (Step 3 - Path B, Fig. 1), adjusting the potential covariates except specific mental disorder for the model. Based on the significant findings from Steps 1-3, the final regression model was carried out. In Step 4 (Path C'), inclusion of a mediator (specific mental disorder) as control, resulting in reduction of the significance or magnitude of the relationship between independent variables (bullying victimization) and dependent variables (suicidality and self harm) indicates that it is the mental disorder that actually triggers suicidality (rather than direct effects of bullying). That is, bullying affects suicidality and self harm via a mental disorder.

However, due to the fact that the Baron and Kenny's approach tends to miss some true mediation effect such as Type II errors (40), it is suggested to calculate the indirect effect and test it for significance. In this study, the Sobel test (41) was used to estimate the indirect effect of bullying victimization on suicidality and self-harm through a mental disorder and for its significance. In this study, according to the Sobel approach, a product is formed by multiplying two coefficients together, the partial regression effect for assumed mediator (mental disorder) predicting dependent variable (suicidality and self-harm), and the simple coefficient for independent variable (bullying victimization) predicting assumed mediator (mental disorder). The strength of the associations between the bullying victimization and suicidality and selfharm was estimated by means of odds ratios (OR) and $95 \%$ confidence intervals.

\section{Results}

\section{General information}

Of the 2166 participants, $28.7 \%$ were victims of traditional bullying and $11.8 \%$ were cyberbullying victims (Table 1). Girls (65.5\%) were clearly more prone to be cyberbullying victims than boys (34.5\%). Almost similar proportions of boys and girls were traditional bullying victims ( $47.9 \%$ of boys and $52.1 \%$ of girls). 
There was a clear difference between genders in involvement in bullying victimization $(p<.0 .05)$. Adolescents in higher school grades and from low to medium-income backgrounds were more likely to be the victim of traditional and cyberbullying. Table 1 also shows that adolescents who spent more time (>2 hours/day) on using internet were more likely to report traditional bullying $(63.7 \%, p=0.005)$ and cyberbullying $(71.4 \%, p<0.001)$ than those who spent $\leq 2$ hours/day. While adolescents spent less than 2 hours a day in electronic gaming were more likely to be bullying victims (73.3\% traditional bullying, $74.1 \%$ cyberbullying) compared to those who spent more the 2 hours. Among the cyberbullying victims, $57.7 \%$ $(p<0.001)$ of adolescents had a history of substance use; while, the percentage is lower $(43.6 \%, p=$ 0.033 ) among the traditional bullying victims. 
Table 1

Sample distribution (i.e. Adolescents aged 12-17-years old)

\begin{tabular}{|c|c|c|c|c|c|}
\hline \multirow[t]{2}{*}{ Characteristics } & \multirow{2}{*}{$\begin{array}{l}\text { Total } \\
\text { n (\%) }\end{array}$} & \multicolumn{2}{|c|}{ Traditional bullying* } & \multicolumn{2}{|c|}{ Cyberbullying^ } \\
\hline & & $\mathrm{n}(\%)$ & $p$-value & $\mathrm{n}(\%)$ & $p$-value \\
\hline Total & $2166(100.0)$ & $622(28.7)$ & & $255(11.8)$ & \\
\hline $\mathrm{Age}^{\mathrm{a}}$ & 14.83 & 14.55 & $<0.001$ & 14.91 & 0.006 \\
\hline Gender & & & 0.011 & & $<0.001$ \\
\hline Boys & $1131(52.2)$ & 298 (47.9) & & $88(34.5)$ & \\
\hline Girls & $1035(47.8)$ & $324(52.1)$ & & $167(65.5)$ & \\
\hline Country of Birth & & & 0.053 & & 0.209 \\
\hline Australia & 1855 (85.6) & 547 (87.9) & & $225(88.2)$ & \\
\hline Overseas & $311(14.4)$ & $75(12.1)$ & & $30(11.8)$ & \\
\hline Location & & & 0.005 & & 0.259 \\
\hline Cities & $1394(64.4)$ & $372(59.8)$ & & $156(61.2)$ & \\
\hline Regional/Remote & 772 (35.6) & $250(40.2)$ & & $99(38.8)$ & \\
\hline Grade & & & $<0.001$ & & 0.002 \\
\hline Grade 7 & $265(12.2)$ & $97(15.6)$ & & $26(10.2)$ & \\
\hline Grade 8 & $283(13.1)$ & $100(16.1)$ & & $33(12.9)$ & \\
\hline Grade 9 & $286(13.2)$ & $80(12.9)$ & & $33(12.9)$ & \\
\hline Grade 10 & 359 (16.5) & $110(17.7)$ & & $57(22.4)$ & \\
\hline Grade 11 & 467 (21.6) & $126(20.3)$ & & $68(26.7)$ & \\
\hline Grade 12 & $506(23.4)$ & 109 (17.5) & & $38(14.9)$ & \\
\hline Family type ${ }^{b}$ & & & $<0.001$ & & $<0.001$ \\
\hline Original & $1324(61.1)$ & $342(55.0)$ & & $126(49.4)$ & \\
\hline Step/Blended/Others & 842 (38.9) & $280(45.0)$ & & $129(50.6)$ & \\
\hline Household income ${ }^{c}$ & & & 0.033 & & 0.235 \\
\hline Low & $503(23.2)$ & 167 (26.9) & & $69(27.1)$ & \\
\hline Medium & $1014(46.8)$ & $283(45.5)$ & & $118(46.3)$ & \\
\hline High & 649 (30.0) & $172(27.6)$ & & $68(26.6)$ & \\
\hline
\end{tabular}




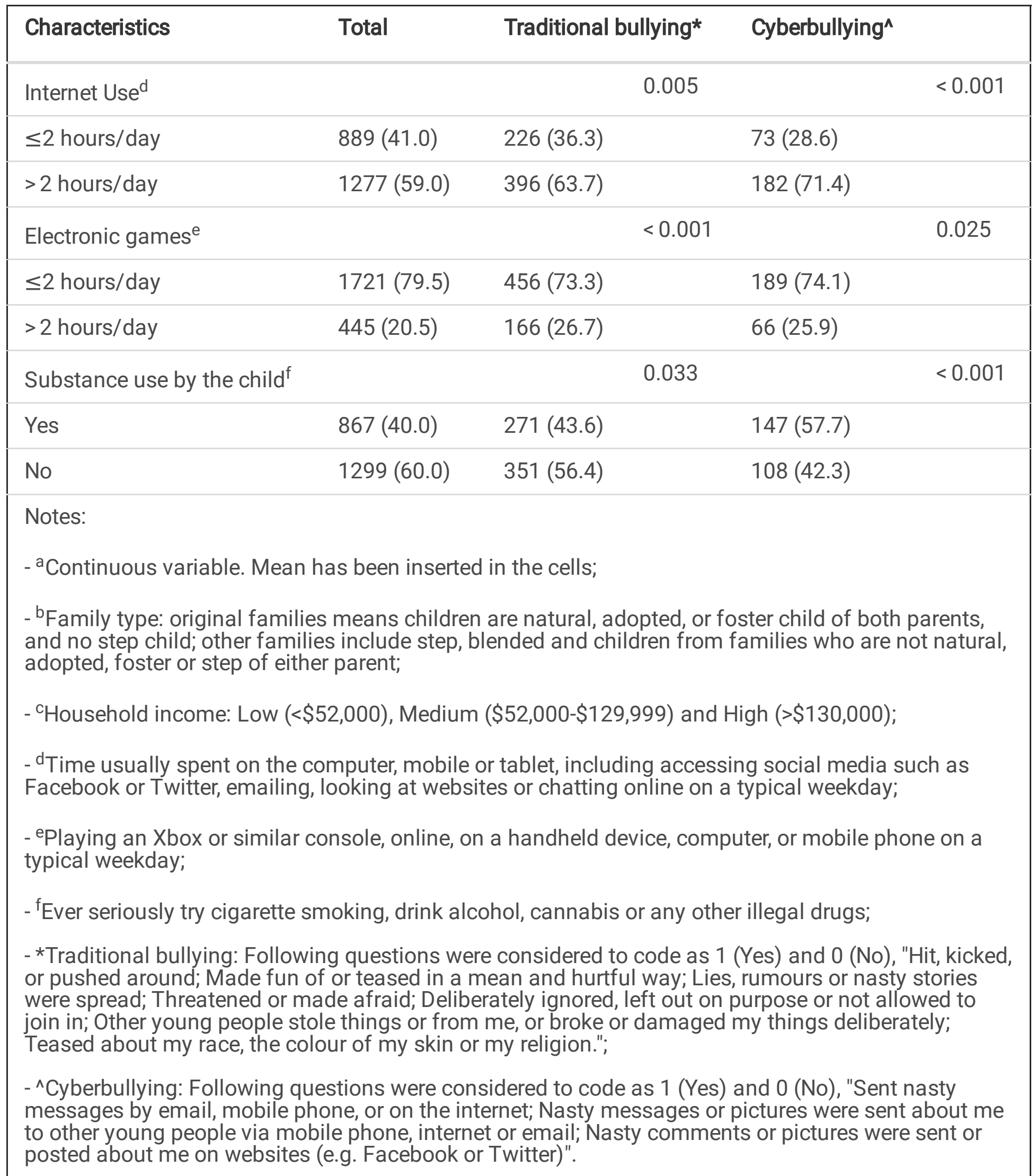

\section{Mental disorder, Suicidality and Self-harm}

The prevalence of mental disorders was as follows - major depressive disorder (11.5\%), ADHD (6.5\%), conduct disorder (1.9\%) and anxiety disorder (7.1\%); while the prevalence of suicidality and self harm were $8 \%$ and $7.8 \%$, respectively (Table 2). Most of the adolescents who had mental disorders, suicidal and 
self-harming behaviour were victims of traditional bullying. About $48 \%, 62 \%, 49 \%$ and $60 \%$ of the adolescents who respectively reported major depressive disorder, ADHD, conduct disorder and anxiety disorder were traditional bullying victims. More than one-third adolescents was a victim of traditional bullying among those who reported suicidality and self-harm (35.6\% and $42.3 \%$, respectively). The percentage of being cyberbullied was also high among the adolescents who reported with mental disorder, suicidality and self-harm. Table 2 illustrates that around $68 \%, 85 \%, 75 \%$ and $82 \%$ of those who had a mental disorder (major depressive disorder, ADHD, conduct disorder and anxiety disorder, respectively) were a victim of cyberbullying. In addition, $51.1 \%$ and $61.3 \%$ of those who respectively reported suicidality and self-harm were cyberbullied. 
Table 2

Prevalence of mental disorders, suicidality and self-harm by bullying victimization (traditional and cyberbullying)

\begin{tabular}{|c|c|c|c|c|c|c|}
\hline & \multicolumn{4}{|l|}{ Mental Disorders $\#$} & \multirow{2}{*}{$\begin{array}{l}\text { Suicidality* } \\
\text { (\%) }\end{array}$} & \multirow{2}{*}{$\begin{array}{l}\text { Self- } \\
\text { harm^ }^{\wedge} \\
(\%)\end{array}$} \\
\hline & $\begin{array}{l}\text { Major Depressive } \\
\text { Disorder (\%) }\end{array}$ & $\begin{array}{l}\text { ADHD } \\
\text { (\%) }\end{array}$ & $\begin{array}{l}\text { Conduct } \\
\text { Disorder (\%) }\end{array}$ & $\begin{array}{l}\text { Anxiety } \\
\text { Disorder (\%) }\end{array}$ & & \\
\hline Total & 248 (11.5) & $\begin{array}{l}141 \\
(6.5)\end{array}$ & $41(1.9)$ & $154(7.1)$ & $174(8.0)$ & $\begin{array}{l}168 \\
(7.8)\end{array}$ \\
\hline \multicolumn{7}{|c|}{$\begin{array}{l}\text { Traditional } \\
\text { bullying }\end{array}$} \\
\hline Yes & $120(52.0)$ & $\begin{array}{l}53 \\
(37.6)\end{array}$ & $21(51.2)$ & $61(39.6)$ & $112(64.4)$ & $\begin{array}{l}97 \\
(57.7)\end{array}$ \\
\hline No & $119(48.0)$ & $\begin{array}{l}88 \\
(62.4)\end{array}$ & $20(48.8)$ & $93(60.4)$ & $62(35.6)$ & $\begin{array}{l}71 \\
(42.3)\end{array}$ \\
\hline$p$-value & $<0.001$ & 0.016 & 0.001 & 0.002 & $<0.001$ & $<.001$ \\
\hline \multicolumn{7}{|c|}{ Cyberbullying } \\
\hline Yes & $80(32.3)$ & $\begin{array}{l}20 \\
(14.2)\end{array}$ & $10(24.4)$ & 28 (18.2) & $85(48.9)$ & $\begin{array}{l}65 \\
(38.7)\end{array}$ \\
\hline No & 168 (67.7) & $\begin{array}{l}121 \\
(85.8)\end{array}$ & 31 (75.6) & $126(81.8)$ & $89(51.1)$ & $\begin{array}{l}103 \\
(61.3)\end{array}$ \\
\hline$p$-value & $<0.001$ & 0.358 & 0.011 & 0.010 & $<0.001$ & $<.001$ \\
\hline \multicolumn{7}{|l|}{ Notes: } \\
\hline \multicolumn{7}{|c|}{$\begin{array}{l}\text { - No. of children having any of the following mental disorders - Major depressive disorder or ADHD or } \\
\text { Anxiety disorder or Conduct disorder; }\end{array}$} \\
\hline \multicolumn{7}{|c|}{ - *Suicidality: Number (\%) of children seriously considered attempting suicide in the past 12 months; } \\
\hline \multicolumn{7}{|c|}{$\begin{array}{l}-\wedge \text { Self-harm: Number (\%) of children deliberately done something to themselves to cause harm or } \\
\text { injury, without intending to end their own life }\end{array}$} \\
\hline
\end{tabular}

\section{Association between bullying victimization (traditional and cyber) and suicidality and self-harm}

Table 3 depicts crude associations between traditional bullying and cyberbullying with suicidality and self-harm. Victims of traditional bullying and cyberbullying incurred a significantly higher risk of suicidality (traditional bullying: COR 5.17, 95\% Cl: 3.62-7.37); cyberbullying: COR 11.02, 95\% Cl: 7.6215.93), and self-harm (traditional bullying: COR 4.13, 95\% Cl: 2.89-5.90; cyberbullying: COR 6.60, 95\% Cl: 4.60-9.46) compared to those adolescents who had not reported such threats. 
Table 3

Crude associations of bullying victimization (traditional and cyberbullying) with suicidality and self-harm

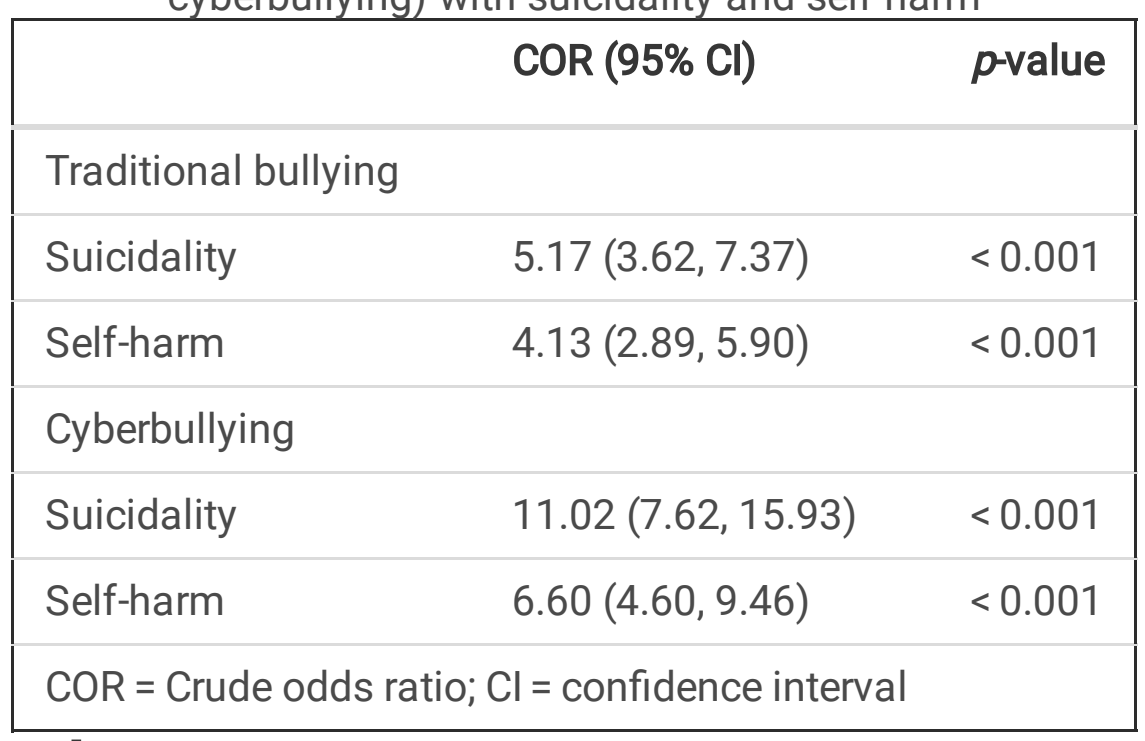

\section{Mediation analysis}

A series of multivariate logistic regression analyses were performed, controlling potential covariates (age, gender, location, school grade, family income, family type, substance use by the child, the time spent on internet use and playing electronic games) and the findings are summarized in Table 4. The regression odd ratio of the Path $\mathrm{C}$ between the independent variables (bullying victimization), and each of the dependent variables (suicidality and self-harm) was significant $(p<0.05)$ except for those who reported ADHD and traditional bullying (Table 4b). In Path B (Table 4a), the associations between the major depressive disorder (mediator) and dependent variables (suicidality and self-harm) for both traditional bullying and cyberbullying victims was found to be significant. In addition, only anxiety disorder found to be significantly associated with suicidality (AOR 2.06, 95\% $\mathrm{Cl} 1.02-4.16$ ) and self-harm (AOR 2.92, 95\% $\mathrm{Cl}$ 1.35-6.31) among traditional bullying victims (Path B, Table 4d). In Path A in Table 4 shows that adolescents who experienced traditional bullying and cyberbullying victimization were respectively 3.07 (95\% Cl, 2.16-4.35) and $3.57(95 \% \mathrm{Cl}, 2.45-5.20)$ times more likely to develop major depressive disorder compared to those who had not reported any bullying victimization. It is also found in Path $A$ that conduct disorder in Table 4c (AOR 2.48, 95\% Cl 1.16-5.28) and anxiety disorder in Table 4d (AOR 1.48, $95 \% \mathrm{Cl} 1.02-2.14$ ) were more likely to be developed among traditional bullying victims. However, the main effect of traditional bullying and cyberbullying victimization on suicidality and self-harm was decreased in most of the cases but still remained significant after controlling for specific mental health disorders (Path C', Table 4). Hence, according to the criteria of Baron and Kenny's approach we can conclude from the Table 4 that major depressive disorder have the mediating effect on the relationship of bullying victimization (both traditional and cyber) with suicidal and self-harming behaviour. Further, anxiety disorder found to be a significant mediator of the association between traditional bullying, suicidality and self-harm. While, ADHD and conduct disorder have no mediating effect on the association between bullying, suicidality and self-harm. 
Table 4

Mediation analyses using Baron and Kenny's approach

\begin{tabular}{|c|c|c|c|c|c|}
\hline & $\begin{array}{l}\text { Path A } \\
\text { (BV } \rightarrow \\
\text { MD) }\end{array}$ & $\begin{array}{l}\text { Path } B(M D \\
\text { Suicidality } \& \overrightarrow{S H})\end{array}$ & 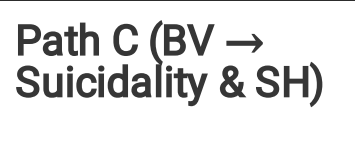 & $\begin{array}{l}\text { Path } C^{\prime}(B V) \rightarrow \\
\text { Suicidality \& SH) }\end{array}$ & $\begin{array}{l}\text { Sobel } \\
\text { Test }^{\dagger}\end{array}$ \\
\hline & $\begin{array}{l}\text { AOR }(95 \% \\
\text { Cl) }\end{array}$ & AOR $(95 \% \mathrm{Cl})$ & $\mathrm{AOR}_{\mathrm{M}-}(95 \% \mathrm{Cl})$ & $\mathrm{AOR}_{\mathrm{M}+}(95 \% \mathrm{Cl})$ & $\begin{array}{l}p \text { - } \\
\text { value }\end{array}$ \\
\hline \multicolumn{6}{|c|}{ 4a. Bullying Victimization $\rightarrow$ Major depresive disorder $\rightarrow$ Suicidality \& Self-harm } \\
\hline \multicolumn{6}{|l|}{$\begin{array}{l}\text { Traditional } \\
\text { bullying }\end{array}$} \\
\hline $\begin{array}{l}\text { Major } \\
\text { depressive } \\
\text { disorder }\end{array}$ & $\begin{array}{l}3.07 * \star \star \\
(2.16 \\
4.35)\end{array}$ & & & & \\
\hline Suicidality & & $\begin{array}{l}9.41 \text { *** }(5.39 \\
16.42)\end{array}$ & $\begin{array}{l}2.59 * \star \\
5.18)\end{array}$ & $\begin{array}{l}2.41^{\star \star}(1.30 \\
4.45)\end{array}$ & $\begin{array}{l}< \\
0.001\end{array}$ \\
\hline Self-harm & & $\begin{array}{l}10.18^{\star \star \star}(5.91 \\
17.51)\end{array}$ & $\begin{array}{l}2.67 * \star \\
5.05)\end{array}$ & $\begin{array}{l}2.63^{\star \star \star *}(1.73 \\
3.99)\end{array}$ & $\begin{array}{l}< \\
0.001\end{array}$ \\
\hline \multicolumn{6}{|c|}{ Cyberbullying } \\
\hline $\begin{array}{l}\text { Major } \\
\text { depressive } \\
\text { disorder }\end{array}$ & $\begin{array}{l}3.57 * \star \star \\
(2.45 \\
5.20)\end{array}$ & & & & \\
\hline Suicidality & & $\begin{array}{l}10.42^{\star \star \star}(4.70 \\
23.09)\end{array}$ & $\begin{array}{l}4.98 * \star \star \\
9.12)\end{array}$ & $\begin{array}{l}4.80 \star \star \\
9.20)\end{array}$ & $<.001$ \\
\hline Self-harm & & $\begin{array}{l}13.17 \star \star \star \\
29.80)\end{array}$ & $\begin{array}{l}2.92 \star * \\
5.70)\end{array}$ & $\begin{array}{l}2.78^{\star *} \\
5.17)\end{array}$ & $\dot{0}_{0.001}$ \\
\hline \multicolumn{6}{|c|}{ 4b. Bullying Victimization $\rightarrow$ ADHD $\rightarrow$ Suicidality \& Self-harm } \\
\hline \multicolumn{6}{|l|}{$\begin{array}{l}\text { Traditional } \\
\text { bullying }\end{array}$} \\
\hline ADHD & $\begin{array}{l}1.38 \text { (0.91, } \\
2.10)\end{array}$ & & & & \\
\hline Suicidality & & $0.91(0.35,2.40)$ & $2.99(0.92,9.69)$ & $\begin{array}{l}2.84 \star \star \\
5.18)\end{array}$ & - \\
\hline Self-harm & & $0.69(0.22,2.09)$ & $3.46(0.64,18.55)$ & $\begin{array}{l}3.19 * * \star \\
5.78)\end{array}$ & - \\
\hline \multicolumn{6}{|c|}{ Cyberbullying } \\
\hline ADHD & $\begin{array}{l}1.51(0.84, \\
2.71)\end{array}$ & & & & \\
\hline Suicidality & & $1.19(0.38,3.73)$ & $\begin{array}{l}13.01^{* *}(3.12 \\
54.12)\end{array}$ & $\begin{array}{l}4.94 \star \star \star \\
9.11)\end{array}$ & - \\
\hline
\end{tabular}




\begin{tabular}{|c|c|c|c|c|c|}
\hline & $\begin{array}{l}\text { Path A } \\
\text { (BV } \rightarrow \\
\text { MD) }\end{array}$ & $\begin{array}{l}\text { Path } B(M D \rightarrow \\
\text { Suicidality \& } \mathrm{SH})\end{array}$ & 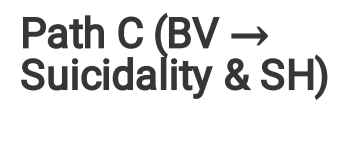 & $\begin{array}{l}\text { Path } \mathrm{C}^{\prime}(\mathrm{BV} \rightarrow \overrightarrow{\mathrm{SH}} \\
\text { Suicidality \& }\end{array}$ & $\begin{array}{l}\text { Sobel } \\
\text { Test }^{\dagger}\end{array}$ \\
\hline Self-harm & & $0.98(0.25,3.81)$ & $\begin{array}{l}13.38 * *(2.47 \\
72.46)\end{array}$ & $\begin{array}{l}2.99 * * \\
5.56)\end{array}$ & - \\
\hline \multicolumn{6}{|c|}{$\begin{array}{l}\text { 4c. Bullying Victimization } \rightarrow \text { Conduct disorder } \rightarrow \\
\text { Suicidality \& Self-harm }\end{array}$} \\
\hline \multicolumn{6}{|l|}{$\begin{array}{l}\text { Traditional } \\
\text { bullying }\end{array}$} \\
\hline $\begin{array}{l}\text { Conduct } \\
\text { disorder }\end{array}$ & $\begin{array}{l}2.48 * \\
(1.16 \\
5.28)\end{array}$ & & & & \\
\hline Suicidality & & $1.10(0.30,3.99)$ & $\begin{array}{l}2.35^{\star \star} \\
4.38)\end{array}$ & $\begin{array}{l}3.00 * \star \star \\
5.38)\end{array}$ & - \\
\hline Self-harm & & $1.14(0.37,3.54)$ & $\begin{array}{l}2.66 \star * \\
4.85)\end{array}$ & $\begin{array}{l}3.44 * \star \star \\
6.14)\end{array}$ & - \\
\hline \multicolumn{6}{|c|}{ Cyberbullying } \\
\hline $\begin{array}{l}\text { Conduct } \\
\text { disorder }\end{array}$ & $\begin{array}{l}2.53(0.98 \\
6.51)\end{array}$ & & & & \\
\hline Suicidality & & $0.68(0.13,3.45)$ & $\begin{array}{l}4.67 \star \star \star \\
9.10)\end{array}$ & $\begin{array}{l}4.99 * \star \star \\
9.14)\end{array}$ & - \\
\hline Self-harm & & $0.84(0.15,4.55)$ & $\begin{array}{l}2.75^{\star \star} \\
5.22)\end{array}$ & $\begin{array}{l}3.12 \star * \star \\
5.71)\end{array}$ & - \\
\hline \multicolumn{6}{|c|}{$\begin{array}{l}\text { 4d. Bullying Victimization } \rightarrow \text { Anxiety disorder } \rightarrow \\
\text { Suicidality \& Self-harm }\end{array}$} \\
\hline \multicolumn{6}{|l|}{$\begin{array}{l}\text { Traditional } \\
\text { bullying }\end{array}$} \\
\hline $\begin{array}{l}\text { Anxiety } \\
\text { disorder }\end{array}$ & $\begin{array}{l}1.48^{*} \\
(1.02, \\
2.14)\end{array}$ & & & & \\
\hline Suicidality & & $2.06 *(1.02,4.16)$ & $\begin{array}{l}9.98 * * \\
38.11)\end{array}$ & $\begin{array}{l}2.79 * \star \\
5.09)\end{array}$ & 0.015 \\
\hline Self-harm & & $\begin{array}{l}2.92 * * \\
6.31)\end{array}$ & $\begin{array}{l}9.89 * * \star \\
26.74)\end{array}$ & $\begin{array}{l}3.25 * \star \star \\
5.89)\end{array}$ & 0.008 \\
\hline \multicolumn{6}{|c|}{ Cyberbullying } \\
\hline $\begin{array}{l}\text { Anxiety } \\
\text { disorder }\end{array}$ & $\begin{array}{l}1.52(0.98 \\
2.37)\end{array}$ & & & & \\
\hline Suicidality & & $1.16(0.39,3.42)$ & $\begin{array}{l}11.99 * \star \star \\
40.45)\end{array}$ & $\begin{array}{l}4.73^{\star \star \star}(2.55 \\
8.80)\end{array}$ & - \\
\hline
\end{tabular}




\begin{tabular}{|c|c|c|c|c|c|}
\hline & $\begin{array}{l}\text { Path A } \\
\text { (BV } \rightarrow \\
\text { MD) }\end{array}$ & $\begin{array}{l}\text { Path } \mathrm{B}(\mathrm{MD} \rightarrow \overrightarrow{ } \\
\text { Suicidality \& SH) }\end{array}$ & $\begin{array}{l}\text { Path C (BV } \vec{~} \\
\text { Suicidality } \& \text { SH) }\end{array}$ & $\begin{array}{l}\text { Path } C^{\prime}(B V=\vec{~} \\
\text { Suicidality \& SH) }\end{array}$ & $\begin{array}{l}\text { Sobel } \\
\text { Test }^{\dagger}\end{array}$ \\
\hline Self-harm & & $1.81(0.56,5.81)$ & $\begin{array}{l}4.47 *(1.10, \\
18.07)\end{array}$ & $\begin{array}{l}2.99 * * *(1.62 \\
5.52)\end{array}$ & - \\
\hline \multicolumn{6}{|l|}{ Notes: } \\
\hline \multicolumn{6}{|c|}{$\begin{array}{l}\text { - BV = Bullying Victimization; MD = Mental disorder (Major depressive disorder/ADHD/Conduct } \\
\text { disorder/Anxiety disorder); } \mathrm{SH}=\text { Self-harm; } \mathrm{AOR}=\text { Adjusted odds ratio; } \mathrm{Cl}=\text { confidence interval }\end{array}$} \\
\hline \multicolumn{6}{|c|}{$\begin{array}{l}\text { - All Model adjusted for age, gender, location, school grade, family income, family type, substance use } \\
\text { by the child, the time spent on internet use and playing electronic games }\end{array}$} \\
\hline \multicolumn{6}{|c|}{$\begin{array}{l}\text { - 4a. Estimating the mediating effect of major depressive disorder on the relationship between BV } \\
\text { and Suicidality/SH }\end{array}$} \\
\hline \multicolumn{6}{|c|}{ - 4b. Estimating the mediating effect of ADHD on the relationship between BV and Suicidality/SH } \\
\hline \multicolumn{6}{|c|}{$\begin{array}{l}\text { - 4c. Estimating the mediating effect of conduct disorder on the relationship between BV and } \\
\text { Suicidality/SH }\end{array}$} \\
\hline \multicolumn{6}{|c|}{$\begin{array}{l}\text { - 4d. Estimating the mediating effect of anxiety disorder on the relationship between BV and } \\
\text { Suicidality/SH }\end{array}$} \\
\hline \multicolumn{6}{|c|}{$\begin{array}{l}\text { - Path A: BV is the independent variable and specific MD (Major depressive disorder/ADHD/Conduct } \\
\text { disorder/Anxiety disorder) is the outcome variable }\end{array}$} \\
\hline \multicolumn{6}{|c|}{$\begin{array}{l}\text { - Path B: MD (Major depressive disorder/ADHD/Conduct disorder/Anxiety disorder) is the independent } \\
\text { variable and Suicidality/SH is the outcome variable }\end{array}$} \\
\hline \multicolumn{6}{|c|}{$\begin{array}{l}\text { - Path C: BV is the independent variable and Suicidality/SH is the outcome variable; } \mathrm{OR}_{\mathrm{M}-} \text { : Odds ratio } \\
\text { from regression model unadjusted for specific MD (Major depressive disorder/ADHD/Conduct } \\
\text { disorder/Anxiety disorder) }\end{array}$} \\
\hline \multicolumn{6}{|c|}{$\begin{array}{l}\text { - Path C': BV is the independent variable and Suicidality/SH is the outcome variable; } \mathrm{OR}_{\mathrm{M}+} \text { : Odds ratio } \\
\text { from regression model adjusted for the specific MD (Major depressive disorder/ADHD/Conduct } \\
\text { disorder/Anxiety disorder) }\end{array}$} \\
\hline \multicolumn{6}{|c|}{$\begin{array}{l}\text { - }{ }^{\dagger} \text { Sobel test: Indirect effect of mediation and its significance was estimated by multiplying two } \\
\text { regression coefficients together, the partial regression effect for MD (Major depressive } \\
\text { disorder/ADHD/Conduct disorder/Anxiety disorder) predicting Suicidality/SH, and the simple } \\
\text { coefficient for BV predicting MDs. Note that Sobel test was performed only for those variables who } \\
\text { fulfilled all the criteria of Baron and Kenny's approach. }\end{array}$} \\
\hline \multicolumn{6}{|c|}{ - Survey weight adjusted } \\
\hline \multicolumn{6}{|c|}{ - $* \star * \mathrm{p}<0.001, * \star \mathrm{p}<0.01,{ }^{\star} \mathrm{p}<0.05$ considered significant } \\
\hline
\end{tabular}

Finally, the Sobel test was performed only for those variables who fulfilled all the criteria of Baron and Kenny's approach to test the indirect effect of mediation, and found significant mediatory role of major depressive disorder and anxiety disorder in the association of traditional bullying with suicidality and selfharm among the 12-17 year-aged adolescents $(p<0.001)$. The mediation analysis also revealed that cyberbullying victimization affects suicidality and self-harm via anxiety disorder $(p<0.05)$. 


\section{Discussion}

This research validated and expanded findings found in previous US and Canadian studies $(9,42,43)$ and indicated that bullying victims (traditional or cyber) are at risk of certain mental disorders such as major depressive disorder and anxiety disorder, which in turn initiates suicidal and self-harming behaviour among adolescents.

In Australia, the prevalence of traditional bullying and cyberbullying was respectively around $29 \%$ and $12 \%$ in adolescents aged 12-17 years; which corroborated the previous studies in conducted Australia (6, $30,35)$ and in other developed countries $(20,44)$. In consistent with past researches, the study found that girls were more likely to be cyber bullied compared to boys; as cyberbullying is web-based and girls may communicate with each other more frequently than boys through text, social media and email $(11,16$, 20). As expected, more time on internet use is found to be common among the cyberbullying victims; may be due to high popularity of hi-tech devices in the modern world among adolescents (45). Like other studies, substance use among bullying victims found to be congruent $(44,46)$.

The present study also estimated that the prevalence of major depressive disorder (11.5\%), ADHD (6.5\%), anxiety disorder (7.1\%), conduct disorder (1.9\%), suicidality (8\%) and non-suicidal self-harm $(7.8 \%)$ in adolescents and found that the figures are not very different from previous studies $(1,47,48)$, which is alarming. The types of bullying (traditional or cyber) experienced among those who diagnosed with a mental disorder was also consistent with prior research $(14,47)$. For example, being cyber bullied was found to be less frequent among the children with mental disorders than traditionally bullied (49). Interestingly, traditionally bullying victims were found to be more involved in suicidal and self-harming behaviour compared to cyberbullying victims, where several studies reported that cyber victimization may have more chances to be involved in suicidality and self-harm than traditional bullying victimization (14, 15).

In accordance with existing research, the results showed that being bullied is significantly associated with the higher risk of developing suicidality and non-suicidal self-harm among adolescents $(50,51)$. This can be due to the fact that being bullied is stressful, which can cause multiple psychopathological changes, including extreme depression, consequently suicidality and/or self-harm $(1,52)$.

In the current study, the mediating role of major depressive disorder on the association of traditional bullying and cyberbullying victimization with suicidality and self-harm is found to be congruent with previous studies $(16,28,53)$. This may be because depressive symptoms may affect moods, interpersonal relationships and performance in school or among peers, which triggers the risk of suicide and /or self-harm $(50,54)$. However, Espelage and Holt (55) found minimal effect of depression on the association between bullying victimization and suicidality and/or self-harm among the US children. Another study involving 10-countries in Europe reported those depressive disorder alone does not have any mediating effect on the association between bullying victimization and suicidality and/or self-harm (11). 
Although only a few studies consider other mental disorders such as anxiety disorder, ADHD and conduct disorder as a mediator $(11,56)$; this study found that the effect of traditional bullying victimization on suicidality and non-suicidal self-harm was mediated by anxiety disorder, which was consistent with previous research findings (50). This is may be due to the fact that the causal associations between bullying, anxiety, suicidality and self harm remain elusive and bullying victims are vulnerable to anxiety which can lead to suicidal and self-harming behaviour (50). Interestingly, the study did not find any mediating effect of ADHD or conduct disorder on the relationship between bullying, suicidal and selfharming behaviour, although previous studies claimed that ADHD and conduct disorder alone can be a potential risk factor for suicidality/self-harm and conduct disorder (57).

The finding that the effect of bullying victimization on suicidality and non-suicidal self-harm is partially mediated by depressive symptoms and anxiety has important implications for clinicians, psychologists, social workers, mental health practitioners and policy makers for preventing suicide globally and in Australia. Assessment of adolescents with mental disorders can include a brief evaluation to determine any history of bullying; as it is acknowledged that the better integration of preventive measures in reliable measures is important if preventive strategies are to be effective $(34,35)$.

The current study has some shortcomings. First, the cross-sectional study design limits to establish the temporal and causal relationship of bullying victimization with suicidality and self-harm. Second, although self-reported data are strong indicators for risk behaviours such as bullying, suicidality and selfharm; measurement error and social desirability bias are likely (58). The survey covered a variety of subjects related to mental health and kept the response burden to a minimum, as much as possible. However, global bullying issues have enough psychometric properties and are often popular in population studies (59).

\section{Conclusion}

The study has demonstrated that being bullied (both traditional and cyber) among adolescents was associated with increased risk of suicidality and self-harm. Most notably, the association of being traditionally bullied with suicidality and self-harm mediated by major depressive disorder and anxiety disorder. Also, major depressive disorder is found to be a mediator in the association of cyberbullying victimization with suicidality and self-harm. Understanding this relationships are important for parents, teachers and practitioners who work with adolescents and others who plan to combat bullying and its related harm at the policy level. The results also emphasize the need to address mental disorders among bullying victims to help prevent the risk of suicidality and self-harm in adolescents worldwide.

\section{Declarations}

\section{Ethical approval and consent to participate}


All participants were informed about the study. Both verbal and written informed consent was obtained from the study participants. (For children under-17 years, parents/guardians completed the written consent form). The Research Ethics Committee of the Australian Government Department of Health (Project 17/2012) and the Research Ethics Committee of the University of Western Australia ethically approved the YMM study.

\section{Consent for publication}

Not applicable

\section{Availability of data and material}

The datasets of Young Minds Matter (YMM) survey data is an open sources data-set, available at the Australian Data Archive (ADA) Dataverse on request (DOI: http://dx.doi.org/10.4225/87/LCVEU3).

\section{Competing interest}

The authors declare that they have no known competing financial interests or personal relationships that could have appeared to influence the work reported in this paper.

\section{Funding}

This research is a part of doctoral dissertation and that did not receive any specific grant from funding agencies in the public, commercial, or not-for-profit sectors.

\section{Author contributions}

Md. Irteja Islam: Conceptualization, Methodology, Software, Data curation, Formal Analysis, Validation, Visualization, Investigation, Writing- Original draft preparation, Writing- Reviewing and Editing; Rasheda Khanam: Supervision, Project administration, Writing- Reviewing and Editing; Enamul Kabir: Supervision, Writing- Reviewing and Editing

\section{Acknowledgements}

The authors would like to thank the University of Western Australia, Roy Morgan Research, the Australian Government Department of Health for conducting the survey, and the Australian Data Archive for the access to the YMM survey dataset. The authors also would like to thank Dr Barbara Harmes for proofreading the manuscript.

\section{References}


1. Ford R, King T, Priest N, Kavanagh A. Bullying and mental health and suicidal behaviour among 14-to 15-year-olds in a representative sample of Australian children. Australian New Zealand Journal of Psychiatry. 2017;51(9):897-908. http://doi.org/10.1177/0004867417700275.

2. Kinchin I, Doran C. The cost of youth suicide in Australia. Int J Environ Res Public Health. 2018;15(4):672. https://doi.org/10.3390/ijerph15040672.

3. Patton GC, Sawyer SM, Santelli JS, Ross DA, Afifi R, Allen NB, et al. Our future: a Lancet commission on adolescent health and wellbeing. The Lancet. 2016;387(10036):2423-78. https://doi.org/10.1016/S0140-6736(16)00579-1.

4. Curtin SC, Heron MP. Death rates due to suicide and homicide among persons aged 10-24: United States, 2000-2017. NCHS Data Brief. 2019;(352):1-8. [Available from: https://pubmed.ncbi.nlm.nih.gov/31751202/].

5. AlHW. Deaths in Australia Canberra: Australian Institute of Health and Welfare; 2019 [Available from: https://www.aihw.gov.au/reports/life-expectancy-death/deaths-in-australia].

6. Islam MI, Khanam R, Kabir E. Bullying victimization, mental disorders, suicidality and self-harm among Australian high schoolchildren: Evidence from nationwide data. Psychiatry Research. 2020:113364. https://doi.org/10.1016/j.psychres.2020.113364.

7. Islam Ml, Khanam R, Kabir E. The use of mental health services by Australian adolescents with mental disorders and suicidality: Findings from a nationwide cross-sectional survey. Plos one. 2020;15(4):e0231180. https://doi.org/10.1371/journal.pone.0231180.

8. ABS

ABS. Causes of Death A. 2018 Canberra: Australian Bureau of Statistics; 2019 [Available from: https://www.abs.gov.au/Causes-of-Death].

9. Hinduja S, Patchin JW. Bullying, cyberbullying, and suicide. Archives of suicide research. 2010;14(3):206-21. https://doi.org/10.1080/13811118.2010.494133.

10. Kowalski RM, Limber SP. Psychological, physical, and academic correlates of cyberbullying and traditional bullying. J Adolesc Health. 2013;53(1):13-20.

https://doi.org/10.1016/j.jadohealth.2012.09.018.

11. Barzilay S, Klomek AB, Apter A, Carli V, Wasserman C, Hadlaczky G, et al. Bullying victimization and suicide ideation and behavior among adolescents in Europe: A 10-country study. J Adolesc Health. 2017;61(2):179-86. https://doi.org/10.1016/j.jadohealth.2017.02.002.

12. Forsyth CJ, Biggar RW Jr, Chen J. Bullied youth: suicide attempts, planning, ideation, and preideation. Criminal Justice Studies. 2020;33(2):170-7. https://doi.org/10.1080/1478601X.2019.1628437.

13. Oexle N, Ribeiro W, Fisher HL, Gronholm PC, Laurens KR, Pan P, et al. Childhood bullying victimization, self-labelling, and help-seeking for mental health problems. Soc Psychiatry Psychiatr Epidemiol. 2020;55(1):81-8. https://doi.org/10.1007/s00127-019-01743-5.

14. Alavi N, Roberts N, Sutton C, Axas N, Repetti L. Bullying victimization (being bullied) among adolescents referred for urgent psychiatric consultation: prevalence and association with suicidality. 
The Canadian Journal of Psychiatry. 2015;60(10):427-31.

http://www.dx.doi.org/10.1177\%2F070674371506001003.

15. Klomek AB, Sourander A, Gould M. The association of suicide and bullying in childhood to young adulthood: A review of cross-sectional and longitudinal research findings. The Canadian Journal of Psychiatry. 2010;55(5):282-8. https://doi.org/10.1177/070674371005500503.

16. Sampasa-Kanyinga H, Roumeliotis $\mathrm{P}, \mathrm{Xu} \mathrm{H}$. Associations between cyberbullying and school bullying victimization and suicidal ideation, plans and attempts among Canadian schoolchildren. PloS one. 2014;9(7):e102145. https://doi.org/10.1371/journal.pone.0102145.

17. Jadambaa A, Thomas HJ, Scott JG, Graves N, Brain D, Pacella R. The contribution of bullying victimisation to the burden of anxiety and depressive disorders in Australia. Epidemiology psychiatric sciences. 2020;29. https://doi.org/10.1017/s2045796019000489.

18. Perren S, Dooley J, Shaw T, Cross D. Bullying in school and cyberspace: Associations with depressive symptoms in Swiss and Australian adolescents. Child Adolesc Psychiatry Mental Health. 2010;4(1):28. https://doi.org/10.1186/1753-2000-4-28.

19. John A, Glendenning AC, Marchant A, Montgomery P, Stewart A, Wood S, et al. Self-harm, suicidal behaviours, and cyberbullying in children and young people: Systematic review. Journal of medical internet research. 2018;20(4):e129. https://doi.org/10.2196/jmir.9044.

20. Messias E, Kindrick K, Castro J. School bullying, cyberbullying, or both: correlates of teen suicidality in the 2011 CDC Youth Risk Behavior Survey. Compr Psychiatr. 2014;55(5):1063-8. https://doi.org/10.1016/j.comppsych.2014.02.005.

21. Extremera N, Quintana-Orts C, Mérida-López S, Rey L. Cyberbullying victimization, self-esteem and suicidal ideation in adolescence: does emotional intelligence play a buffering role? Frontiers in psychology. 2018;9:367. https://dx.doi.org/10.3389\%2Ffpsyg.2018.00367.

22. Agnew R. Foundation for a general strain theory of crime and delinquency. Criminology. 1992;30(1):47-88. https://www.ncjrs.gov/App/Publications/abstract.aspx?ID=136257.

23. Patchin JW, Hinduja S. Traditional and nontraditional bullying among youth: A test of general strain theory. Youth Society. 2011;43(2):727-51. https://doi.org/10.1177\%2F0044118X10366951.

24. Wallace LH, Patchin JW, May JD. Reactions of Victimized Youth: Strain as an Explanation of School Delinquency. Western criminology review. 2005;6(1). [Available from: http://westerncriminology.org/documents/WCR/v06n1/article_pdfs/wallace.pdf].

25. Zubrick SR, Hafekost J, Johnson SE, Lawrence D, Saw S, Sawyer M, et al. Suicidal behaviours: prevalence estimates from the second Australian Child and Adolescent Survey of Mental Health and Wellbeing. Australian. \& New Zealand Journal of Psychiatry. 2016;50(9):899-910. https://www.doi.org/10.1177\%2F0004867415622563.

26. Zubrick SR, Hafekost J, Johnson SE, Lawrence D, Saw S, Sawyer M, et al. Self-harm: prevalence estimates from the second Australian child and adolescent survey of mental health and wellbeing. Australian New Zealand Journal of Psychiatry. 2016;50(9):911-21. https://doi.org/10.1177/0004867415617837. 
27. Quintana-Orts C, Rey L, Mérida-López S, Extremera N. What bridges the gap between emotional intelligence and suicide risk in victims of bullying? A moderated mediation study. J Affect Disord. 2019;245:798-805. https://doi.org/10.1016/j.jad.2018.11.030.

28. Bauman S, Toomey RB, Walker JL. Associations among bullying, cyberbullying, and suicide in high school students. Journal of adolescence. 2013;36(2):341-50.

https://doi.org/10.1016/j.adolescence.2012.12.001.

29. Hemphill SA, Kotevski A, Heerde JA. Longitudinal associations between cyber-bullying perpetration and victimization and problem behavior and mental health problems in young Australians. International journal of public health. 2015;60(2):227-37. https://doi.org/10.1007/s00038-014-06449.

30. Jadambaa A, Thomas HJ, Scott JG, Graves N, Brain D, Pacella R. Prevalence of traditional bullying and cyberbullying among children and adolescents in Australia: A systematic review and metaanalysis. Australian New Zealand Journal of Psychiatry. 2019:0004867419846393. https://doi.org/10.1177/0004867419846393.

31. Hafekost J, Lawrence D, Boterhoven de Haan K, Johnson SE, Saw S, Buckingham WJ, et al. Methodology of young minds matter: The second Australian child and adolescent survey of mental health and wellbeing. Australian New Zealand Journal of Psychiatry. 2016;50(9):866-75. https://www.doi.org/10.1177\%2F0004867415622270.

32. Lawrence D, Hafekost J, Johnson SE, Saw S, Buckingham WJ, Sawyer MG, et al. Key findings from the second Australian child and adolescent survey of mental health and wellbeing. Australian New Zealand Journal of Psychiatry. 2016;50(9):876-86. https://doi.org/10.1177/0004867415617836.

33. CDC. Adolescent and School Health: YRBSS Questionnaires: Centers for Disease Control and Prevention; 2014 [Available from: https://www.cdc.gov/healthyyouth/data/yrbs/questionnaires.htm].

34. Cross D, Shaw T, Hadwen K, Cardoso P, Slee P, Roberts C, et al. Longitudinal impact of the Cyber Friendly Schools program on adolescents' cyberbullying behavior. Aggressive behavior. 2016;42(2):166-80. https://doi.org/10.1002/ab.21609.

35. Thomas HJ, Connor JP, Lawrence DM, Hafekost JM, Zubrick SR, Scott JG. Prevalence and correlates of bullying victimisation and perpetration in a nationally representative sample of Australian youth. Australian New Zealand Journal of Psychiatry. 2017;51(9):909-20. https://www.doi.org/10.1177/0004867417707819.

36. Rikkers W, Lawrence D, Hafekost J, Zubrick SR. Internet use and electronic gaming by children and adolescents with emotional and behavioural problems in Australia-results from the second Child and Adolescent Survey of Mental Health and Wellbeing. BMC Public Health. 2016;16(1):399. https://doi.org/10.1186/s12889-016-3058-1.

37. APA. Diagnostic and statistical manual of mental disorders. BMC Med. 2013;17:133-7. [Available from: https://www.psychiatry.org/psychiatrists/practice/dsm].

38. Fisher PW, Shaffer D, Piacentini JC, Lapkin J, Kafantaris V, Leonard H, et al. Sensitivity of the Diagnostic Interview Schedule for Children, (DISC-2.1) for specific diagnoses of children and 
adolescents. Journal of the American Academy of Child Adolescent Psychiatry. 1993;32(3):666-73. http://doi.org/10.1097/00004583-199305000-00026.

39. Baron RM, Kenny DA. The moderator-mediator variable distinction in social psychological research: Conceptual, strategic, and statistical considerations. J Personal Soc Psychol. 1986;51(6):1173. https://psycnet.apa.org/doi/10.1037/0022-3514.51.6.1173.

40. MacKinnon DP, Fairchild AJ, Fritz MS. Mediation analysis. Annu Rev Psychol. 2007;58:593-614. https://doi.org/10.1146/annurev.psych.58.110405.085542.

41. Sobel ME. Asymptotic confidence intervals for indirect effects in structural equation models. Sociological methodology. 1982;13:290-312. https://www.jstor.org/stable/270723.

42. Goebert D, Else I, Matsu C, Chung-Do J, Chang JY. The impact of cyberbullying on substance use and mental health in a multiethnic sample. Matern Child Health J. 2011;15(8):1282-6. https://doi.org/10.1007/s10995-010-0672-x.

43. Schneider SK, O'donnell L, Stueve A, Coulter RW. Cyberbullying, school bullying, and psychological distress: A regional census of high school students. American journal of public health. 2012;102(1):171-7. https://dx.doi.org/10.2105\%2FAJPH.2011.300308.

44. Litwiller BJ, Brausch AM. Cyber bullying and physical bullying in adolescent suicide: the role of violent behavior and substance use. J Youth Adolesc. 2013;42(5):675-84. https://doi.org/10.1007/s10964-013-9925-5.

45. Anderson EL, Steen E, Stavropoulos V. Internet use and Problematic Internet Use: A systematic review of longitudinal research trends in adolescence and emergent adulthood. International Journal of Adolescence Youth. 2017;22(4):430-54. https://doi.org/10.1080/02673843.2016.1227716.

46. Thomas HJ, Chan GC, Scott JG, Connor JP, Kelly AB, Williams J. Association of different forms of bullying victimisation with adolescents' psychological distress and reduced emotional wellbeing. Australian New Zealand Journal of Psychiatry. 2016;50(4):371-9. https://doi.org/10.1177/0004867415600076.

47. Bannink R, Broeren S, van de Looij-Jansen PM, de Waart FG, Raat H. Cyber and traditional bullying victimization as a risk factor for mental health problems and suicidal ideation in adolescents. PloS one. 2014;9(4):e94026. https://doi.org/10.1371/journal.pone.0094026.

48. Islam MI, Kabir E, Khanam R, Suicidality. Mental Disorder and the Utilization of Mental Health Services among Australian Adolescents. Children and Youth Services Review. 2020:104821. https://dx.doi.org/10.1371\%2Fjournal.pone.0231180.

49. Bonanno RA, Hymel S. Cyber bullying and internalizing difficulties: Above and beyond the impact of traditional forms of bullying. J Youth Adolesc. 2013;42(5):685-97. https://doi.org/10.1007/s10964013-9937-1.

50. Hong JS, Kral MJ, Sterzing PR. Pathways from bullying perpetration, victimization, and bully victimization to suicidality among school-aged youth: A review of the potential mediators and a call for further investigation. Trauma Violence Abuse. 2015;16(4):379-90. https://doi.org/10.1177/1524838014537904. 
51. Tang JJ, Yu Y, Wilcox HC, Kang C, Wang K, Wang C, et al. Global risks of suicidal behaviours and being bullied and their association in adolescents: School-based health survey in 83 countries. EClinicalMedicine. 2020;19:100253. https://doi.org/10.1016/j.eclinm.2019.100253.

52. Baiden $P$, Tadeo SK. Investigating the association between bullying victimization and suicidal ideation among adolescents: evidence from the 2017 Youth Risk Behavior Survey. Child Abuse Neglect. 2020;102:104417. https://doi.org/10.1016/j.chiabu.2020.104417.

53. Baiden P, Stewart SL, Fallon B. The mediating effect of depressive symptoms on the relationship between bullying victimization and non-suicidal self-injury among adolescents: Findings from community and inpatient mental health settings in Ontario, Canada. Psychiatry Res. 2017;255:23847. https://doi.org/10.1016/j.psychres.2017.05.018.

54. Lewinsohn PM, Rohde P, Seeley JR. Psychosocial risk factors for future adolescent suicide attempts. J Consult Clin Psychol. 1994;62(2):297. https://doi.org/10.1037//0022-006x.62.2.297.

55. Espelage DL, Holt MK. Suicidal ideation and school bullying experiences after controlling for depression and delinquency. J Adolesc Health. 2013;53(1):27-31. https://doi.org/10.1016/j.jadohealth.2012.09.017.

56. Kim YS, Koh Y-J, Leventhal B. School bullying and suicidal risk in Korean middle school students. Pediatrics. 2005;115(2):357-63. https://doi.org/10.1542/peds.2004-0902.

57. Chen Y-Y, Chen Y-L, Gau SS-F. Attention-deficit hyperactivity disorder and suicidality: the mediating effects of psychiatric comorbidities and family function. J Affect Disord. 2019;242:96-104. https://doi.org/10.1016/j.jad.2018.08.023.

58. Cornell D, Bandyopadhyay S. The assessment of bullying. The international handbook of school bullying. Nov. 2009;11:265-76.

59. Solberg ME, Olweus D. Prevalence estimation of school bullying with the Olweus Bully/Victim Questionnaire. Aggressive Behavior: Official Journal of the International Society for Research on Aggression. 2003;29(3):239-68. https://doi.org/10.1002/ab.10047.

\section{Figures}




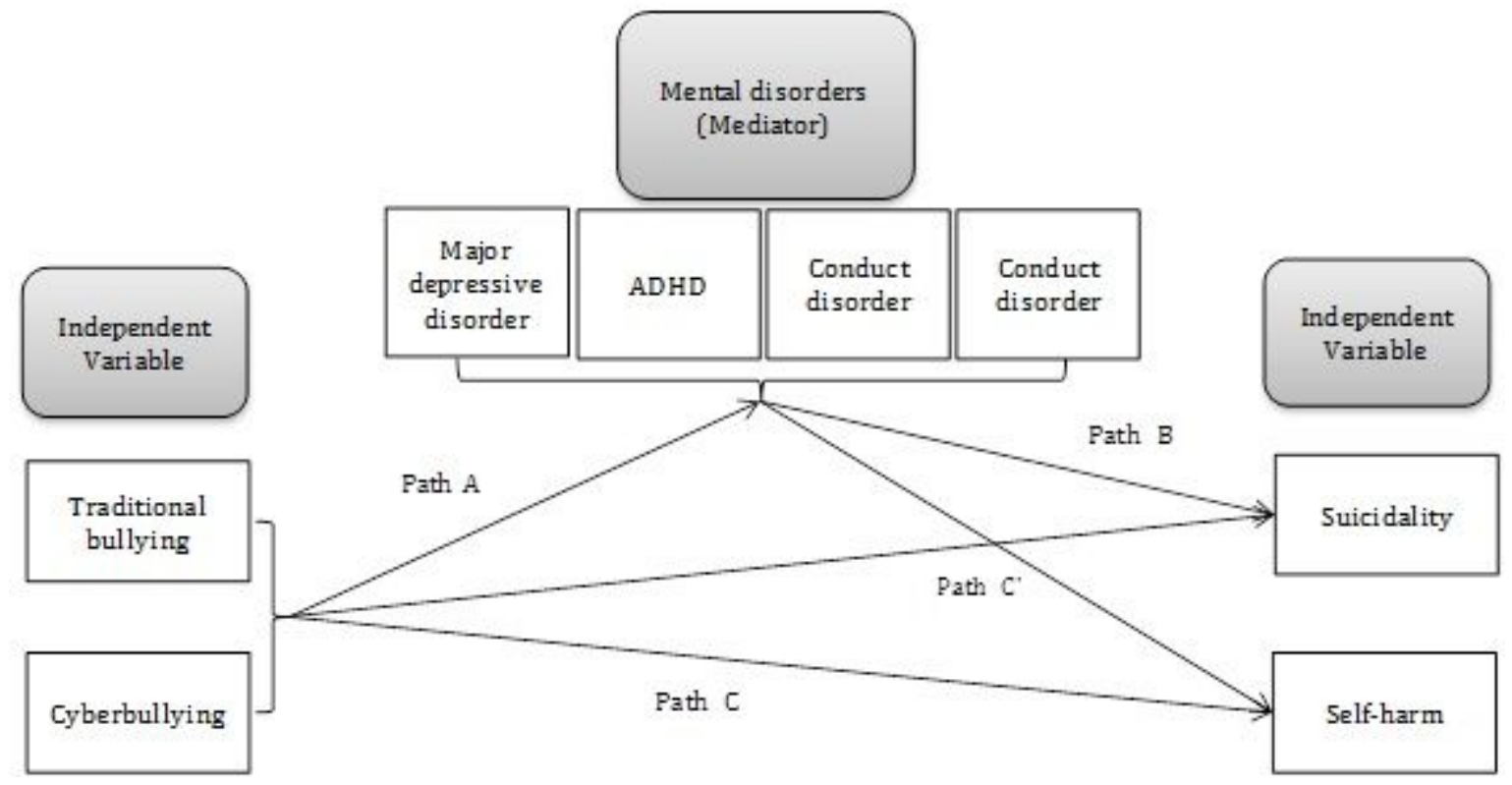

\section{Figure 1}

Hypothesized mediational model to study the effect of mental disorders in the relationship between bullying victimization, suicidality and self-harm 